\title{
THE EFFECT OF SERVICE QUALITY PERCEPTIONS OF STUDENTS WHICH RECEIVE EDUCATION AT UNDERGRADUATE LEVEL ONSATISFACTION LEVEL
}

DOI: 10.17261/Pressacademia.2020.1250

PAP- V.11-2020(22)-p.110-114

\section{Inci Fatma Dogan}

Kahramanmaras Sutcu Imam University, Turkoglu Vocational School, Management and Organizations, Kahramanmaras, Turkey. ikurtulgan@gmail.com, ORCID: 0000-0002-9749-2878

To cite this document

Dogan, I.F. (2020). The effect of service quality perceptions of students which receive education at undergraduate level on satisfaction level, PressAcademia Procedia (PAP), V.11, p.110-114

Permanent link to this document: http://doi.org/10.17261/Pressacademia.2020.1250

Copyright: Published by PressAcademia and limited licensed re-use rights only.

\section{ABSTRACT}

Purpose- The purpose of this study is to evaluate the service quality of students studying at a vocational high school within a state university and to measure the effect of their perceptions about service quality on student satisfaction. In addition, it is aimed to determine whether there is a difference in students' perceptions of service quality and satisfaction depending on their demographic characteris tics (gender, age, department where they study).

Methodology- The data of the study were obtained from the students of Türkoğlu Vocational School of Kahramanmaraş Sütçü imam University using a survey method. Students' perception of service quality is handled in a multidimensional structure including tangibles, reliability, responsiveness, assurance and empathy. SPSS program was used for data analysis. Frequency analysis, Independent $\mathrm{t}$-Test, ANOVA, correlation and regression analysis were used.

Findings- As a result of testing the hypotheses developed in line with the purpose of the study, it was found that the quality of service was effective on satisfaction of the students. When examined separately in terms of service quality dimensions, empathy dimension is more effective on students' satisfaction than other dimensions; it was found that the responsiveness dimension was also less effective. In addition, it was found that female and male students' perceptions of service quality and satisfaction differ from each other. Also it was concluded that students' perceptions of service quality and satisfaction differ from each other according to their departments.

Conclusion- Based upon the analysis showed that there were significant relationships between the variables.

Keywords: Quality, service quality, service quality in higher education, vocational schools.

JEL Codes: M10, M19.

\section{ÖNLISANS DÜZEYINDE ÖĞRENIM GÖREN ÖĞRENCILERIN HIZMET KAL̇TESI ALGILARININ MEMNUNIYET DÜZEYLERINE ETKISi}

\section{ÖZET}

Amaç- Bu çalışmada bir devlet üniversitesi bünyesindeki meslek yüksekokulunda öğrenim gören öğrencilerin sunulan hizmet kalitesini değerlendirmeleri istenmiş ve hizmet kalitesine ilişkin algılarının öğrenci memnuniyetleri üzerindeki etkisinin ölçülmesi ama çlanmıştır. Ayrıca öğrencilerin demografik özelliklerine (cinsiyet, yaş, öğrenim gördükleri bölüm gibi) bağlı olarak hizmet kalitesine ve memnuniyet düzeylerine ilişkin algılarında bir farklılı̆ın olup olmadığı belirlenmek istenmiştir.

Yöntem- Çalışmanın verileri Kahramanmaraş Sütçü İmam Üniversitesi'ne bağlı Türkoğlu Meslek Yüksekokulu öğrencilerinden anket tekniğ ile elde edilmiştir. Öğrencilerin hizmet kalitesi algısı fiziksel özellikler, güvenilirlik, heveslilik, güven ve empati olmak üzere çok boyutlu bir yapıda ele alınmıştır. Verilerin analizi için SPSS programından faydalanılmıştır. Çalışmada frekans analizi, Bağımsız t-Testi, ANOVA, korelasyon ve regresyon analizleri kullanılmıştır.

Bulgular- Çalışmanın amacı doğrultusunda geliştirilen hipotezlerin test edilmesi sonucunda hizmet kalitesinin tüm boyutla rı ile öğrencilerin memnuniyetleri üzerinde etkili olduğu bulunmuştur. Hizmet kalitesi boyutları açısından ayrı ayrı incelendiğinde empati boyutunun öğrencilerin memnuniyetleri üzerinde diğer boyutlara göre daha etkili; heveslilik boyutunun da daha az etkili olduğu bulgusuna ulaşılmıştır. Ayrıca kadın ve erkek öğrencilerin hizmet kalitesi algılarının ve memnuniyet düzeylerinin birbirinden farklı olduğu bulgusu elde edilmiştir. Yine öğrencilerin öğrenim gördükleri bölümlere göre hizmet kalitesine ilişkin alg ılarının ve memnuniyet düzeylerinin birbirinden farklı olduğu sonucuna ulaşılmıştır.

Sonuç- Yapılan analizler sonucunda değişkenler arasında anlamlı ilişkiler olduğu ve hizmet kalitesinin öğrencilerin memnuniyet düzey leri üzerinde pozitif etkiye sahip olduğu sonucuna ulaşılmıştır.

Anahtar Kelimeler: Kalite, hizmet kalitesi, yükseköğretimde hizmet kalitesi, meslek yüksekokulları. JEL Kodları: M10, M19. 


\section{Gíriş}

Ülkemizde kamu üniversiteleri yanında vakıf üniversitelerinin de kurulması ve sayılarının gün geçtikçe artması, periyodik aralıklarla üniversitelerin belirli kriterlere göre değerlendirilip bir sıralamaya gidilmesi üniversiteler arasındaki rekabeti artırmıştır (Cevher, 2016). Artan rekabet ortamında ülke kalkınmasının sağlanması, toplumun ihtiyaç ve beklentilerinin karşılanması ve toplumsal refah düzeyinin artırılması noktasında fiziki sermaye kadar beşerî sermaye ve beşerî sermayenin niteliğini belirleyen temel unsur eğitim önem kazanmaktadır. Sektörler için teknik bilgi ve beceriye sahip ara eleman ihtiyacının karşılanmasında mesleki ve teknik eğitimin kalitesi oldukça önem taşımaktadır. Bu açıdan bakıldığında meslek yüksekokullarında kalifiye işgücü potansiyeline sahip olmak için sunulan eğitimin hizmet kalitesi oldukça hayati önemdedir. Üniversitelerde hizmeti alan ve değerlendiren açısından hizmet kalitesi oldukça önem kazanmıştır (Ceylan, 1997). Rekabet ortamında birbirleriyle kıyaslanan üniversitelerde hem mevcut öğrenci memnuniyetini yüksek tutmak hem de aday öğrencileri cezbetmesi açısından sunulan hizmetlerde kaliteyi yakalamak oldukça kilit bir unsur haline gelmiştir. Derslik, kütüphane alanlarının say ısı gibi fiziksel koşulların yeterliliği, öğretim elemanlarının ders anlatım şekilleri, donanımları anlamında eğitim ve öğretimin kalitesi, idari personelin niteliği, davranış tarzları, ulaşım, spor ve kültürel faaliyetler gibi alanlarda belirli standartların yakalanıp hizmet kalitesinin yüksek olmasına dikkat edilmeye başlanmıştır (Tayyar ve Dilşeker, 2012). Bu anlamda üniversitelerde sunulan hizmetlerin kalitesini değerlendirme noktasında öğrenciler önemli kaynaklardan bir tanesidir. Nasıl ki müşteriye yönelik memnuniyet anlayışı doğrultusunda hangi hizmetin kaliteli olduğuna müşteriler karar veriyorsa üniversitelerde de müşteri olarak ilk akla gelen öğrenciler olmaktadır. Öğrencilerin her konuda ihtiyaç ve beklentilerinin en iyi şekilde karşılanması gerekmektedir. Çünkü öğrencilerin yaptığı değerlendirmeler kalitenin artırılması noktasında önemli bir veri kaynağıdır. Bu doğrultuda Türkoğlu Meslek Yüksekokulunda da eğitim-öğretim faaliyetlerinin etkinliğini artırmak, araştırma-geliştirme çalışmalarına hız kazandırmak, idari hizmetler açısından destek alabilmek ve kaliteyi artırabilmek adına çeşitli çalışmalar yapılmaktadır (http://turkoglumyo.ksu.edu.tr, 2019).

Bu bilgiler ışığında bu çalışmada bir devlet üniversitesi bünyesindeki meslek yüksekokulunda öğrenim gören öğrencilerin sunulan hizmet kalitesini değerlendirmeleri istenmiş ve hizmet kalitesine ilişkin algılarının öğrenci memnuniyetleri üzerindeki etkisinin ölçülmesi amaçlanmıştır. Ayrıca öğrencilerin demografik özelliklerine (cinsiyet, yaş, öğrenim gördükleri bölüm gibi) bağlı olarak hizmet kalitesine ilişkin algılarında ve memnuniyet düzeylerinde bir farklılı̆ın olup olmadığı belirlenmek istenmiştir. Çalışmanın verileri anket tekniği ile elde edilmiştir. Çalışmanın amacı doğrultusunda hazırlanan anketler 2019-2020 eğitim-öğretim yılında Kasım ayında öğrencilere uygulanmıştır. Elde edilen verilerin analizi sonucunda değişkenler arasında anlamlı ilişkiler olduğu ve hizmet kalitesinin öğrencilerin memnuniyet düzeyleri üzerinde pozitif etkiye sahip olduğu sonucuna ulaşılmıştır.

\section{YÖNTEM}

Bu çalışma, Türkoğlu Meslek Yüksekokulunun Yönetim ve Organizasyon, Sosyal Hizmet ve Danışmanlık, Mülkiyet Koruma ve Güvenlik ile Bitkisel ve Hayvansal Üretim bölümlerinde öğrenim gören birinci ve ikinci sınıf öğrencilerinin hizmet kalitesine ilişkin algılarını anket tekniğiyle elde etmeyi amaçlamaktadır. Meslek yüksekokulunda eğitim-öğretim görmekte olan 464 kayıtlı öğrenci bulunmaktadır. Aktif olarak derslere katılım sağlayan öğrenci sayısı ise 309 olup bu öğrencilere anketler dağıtılmıştır. Çalışma kapsamında geri dönen 217 anketin 203 'ünün kullanılabilir olduğu görülmüştür. Bu veriye göre anakütlenin \%65,69'una ulaşılmıştır.

Anket formunda yer alan soruların hazırlanmasında eğitim sektöründe, özellikle yükseköğretim kurumlarında yapılmış olan çalışmalardan faydalanılmıştır. Ankette yer alan hizmet kalitesi kavramını detaylı bir biçimde ölçebilmek ve öğrencilerin beklentilerini belirleyebilmek amacıyla literatürde en yaygın kullanılan Parasuraman, Zeithaml ve Berry $(1985,1988,1990)$ tarafından geliştirilen SERVQUAL ölçeği kullanılmıştır. Ölçekte öğrencilerin hizmet kalitesi algısı fiziksel özellikler, güvenilirlik, heveslilik, güven ve empati olmak üzere çok boyutlu bir yapıda ele alınmıştır. Ölçek 22 maddelik sorudan oluşmaktadır. Memnuniyeti ölçmeye yönelik ise Kajenthiran ve Karunanithy (2015) tarafından geliştirilen 4 sorudan oluşan ölçek kullanılmıştır. Hizmet kalitesini ve memnuniyeti ölçmeye yönelik önermelerin değerlendirilmesinde, “1: Kesinlikle katılmıyorum, 2: Katılmıyorum, 3: Kararsızım, 4: Katılıyorum ve 5: Kesinlikle katılıyorum” şeklinde beşli Likert ölçeği kullanılmıştır. Araştırmanınamaçları doğrultusunda elde edilen veriler SPSS istatistik paket programıkullanılarak analiz edilmiştir. Öncelikle verilerin normal dağılıma uygun olmadığını test etmek için Kolmogorov-Smirnov testi uygulanmıştır. Bu test sonucunda elde edilen değer verilerin normal dağılıma uygun olduğunu göstermiştir ve bu nedenle parametrik analiz yöntemlerinin uygulanmasına karar verilmiştir.

\section{BULGULAR}

Araştırma değişkenlerinin güvenir liliği, literatürde yaygın olarak kullanılan Cronbach Alfa değerleri ile ölçümlenmiştir. Hiz met kalitesine ilişkin önermelerden iki tanesi güvenilirliği düşürmesi nedeniyle kapsam dışında tutulmuştur ve sonraki analizlere 20 önerme ile devam edilmiştir. Hizmet kalitesi ile hizmet kalitesinin güvenilirlik boyutu ve memnuniyet Özdamar (1999)'ın yüksek güvenilir düzey olarak tanım ladığı 0,81 ve üzerinde bulunmuştur. Diğer değişkenlerin tamamının değeri ise Özdamar (1999)'ın orta güvenilir düzey olarak tanımla dığı 0,61 ve üzerindedir (Yaşar, 2014: 63).

Tablo 1: Araştırmanın Değişkenlerinin Güvenilirliği

\begin{tabular}{lcc}
\hline Değişkenler & Cronbach Alfa Değeri & Önerme Sayısı \\
Hizmet Kalitesi &, 916 & 20 \\
Fiziksel Özellikler &, 729 & 4 \\
Güvenilirlik &, 838 & 5 \\
Heveslilik &, 605 & 3 \\
Güven &, 788 & 3 \\
Empati &, 793 & 5 \\
Memnuniyet &, 943 & 4 \\
\hline
\end{tabular}


Katılımcıların \%45,9’ u (90) kadın, \%54,1'i (106) erkektir. Katılımcıların büyük çoğunluğu $(\% 68,8)$ yaşı 20 ve altı yaş aralığındadır. \%29' u 21 -30 yaş aralığında, \%2,1'i ise 31 ve üstü yaş aralığındadır. Katılımcılardan 5'i $(\% 2,6)$ evli, 189'u $(\% 96,4)$ bekar ve 2' si $(\% 1)$ eşinden ayrılmıştır. Öğrenim gördükleri bölümlere göre incelendiğinde katılımcıların sayısının Yönetim ve Organizasyon, Bitkisel ve Hayvansal Üretim ile Sosyal Hizmet ve Danışmanlık bölümlerinde eşit sayıda (34 öğrenci, \%17,1) olduğu görülmüştür. Mülkiyet Koruma ve Güvenlik bölümünde okuyan öğrenci sayısı ise $97(\% 48,7)$ dir.

Araştırmada ele alınan hizmet kalitesi ve memnuniyet değişkenlerine ait frekans dağıımlarına ilişkin bilgilere tablo 2' de yer verilmiştir

Tablo 2: Araştırma Değişkenlerine Ait Ortalama ve Standart Sapma Değerleri

\begin{tabular}{lcc}
\hline Değişkenler & Ort & s.s. \\
\hline Hizmet Kalitesi & 2,995 &, 871 \\
Fiziksel Özellikler & 2,594 &, 936 \\
Güvenilirlik & 2,974 & 1,030 \\
Heveslilik & 3,287 & 1,350 \\
Güven & 3,364 & 1,157 \\
Empati & 2,762 & 1,012 \\
Memnuniyet & 2,020 & 1,157 \\
\hline
\end{tabular}

Katılımcıların hizmet kalitesi algılarını ölçmek amacıyla sorulan önermelere verdikleri yanıtlar incelendiğinde genel algı düzeyi ortalamasının kararsız $(2,995)$ seçeneği etrafında yoğunlaştı̆̆ı görülmektedir. Buna göre katılımcıların kendilerine sunulan hizmetlerin yeterli düzeyde beklentilerini karşılamadığı ifade edilebilir. Hizmet kalitesi boyutları açısından ayrıayrı ele alındığında fiziksel özellik lere ilişkin algı düzeyi ortalamasının 2,594; güvenilirliğe ilişkin ortalamanın 2,974; hevesliliğe ilişkin ortalamanın 3,287; güvene ilişkin ortalamanın 3,364 ve empati değişkenine ilişkin ortalamanın 2,762 olduğu bulgusuna ulaşılmıştır. Elde edilen bu sonuçlara göre en yüksek ortalamaya sahip boyut heveslilik, en düşük ortalamaya sahip boyut ise fiziksel özellikler boyutu olmuştur .

Araştırma kapsamında ileri sürülen hipotezleri test edebilmek üzere öncelikle değişkenler arasında korelasyonun varlığı gerekmektedir. Değişkenler arasındaki korelasyon analizi sonuçları aşağıda tablo 3’ de sunulmaktadır.

Tablo 3: Araştırma Değişkenlerinin Korelasyon Değerleri

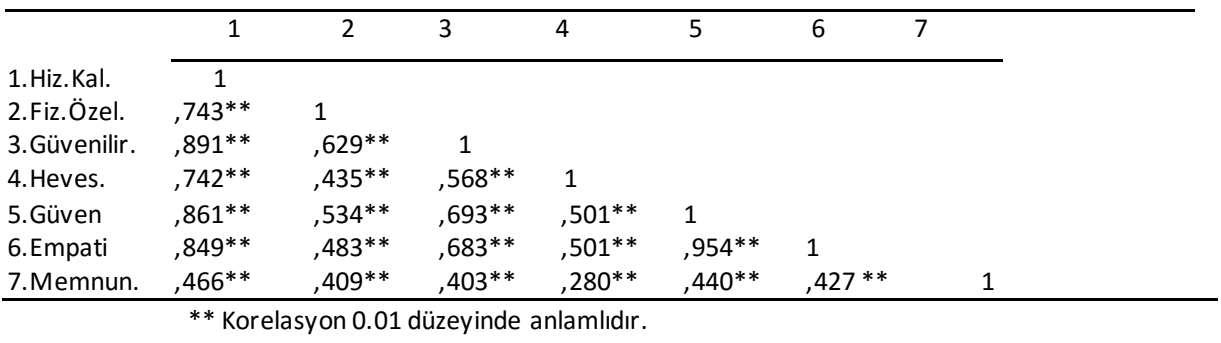

Yapılan korelasyon analizi sonucuna göre hizmet kalitesi ve tüm alt boyutları ile memnuniyet arasında $p<.05$ düzeyinde anlamlı ve pozitif yönlü ilişkiler olduğu görülmektedir. Ölçekler arasındaki ilişkiler, " $r=0,00-0,25$ aralığında ilişki çok zayıf, $r=0,26-0,49$ aralığında ilişki zayıf, $r=$ 0,50-0,69 aralığında ilişki orta, $r=0,70-0,89$ aralığında ilişki yüksek ve $r=0,90-1,00$ aralığında ilişki çok yüksek" şeklinde değerlendirilmiştir (Kalaycı, 2006: 116). Buna göre heveslilik hizmet kalitesi boyutu ile memnuniyet arasındaki ilişkinin dışında tüm diğer değişkenler arasında orta düzeyde ilişkinin olduğu görülmüştür. Heveslilik ile memmuniyet arasındaki ilişkinin $(r=, 208)$ ise zayıf düzeyde olduğu bulgusuna ulaşılmıştır.

Tablo 4: Hizmet Kalitesinin Memnuniyet Üzerindeki Etkisine Yönelik Regresyon Analizi

\begin{tabular}{lcll}
\hline Değişkenler & Beta & t değeri & p değeri \\
\hline Memnuniyet &, 466 & 7,280 &, 000 \\
& $\Delta \mathbf{R} 2=, \mathbf{2 1 3}$ & $\mathrm{F}=53, \mathbf{0 0 2}$ &, 000 \\
\hline
\end{tabular}

Araştırmada geliştirilen “H1: Öğrencilerin hizmet kalitesi algıları memnuniyet düzeylerini pozitif ve anlamlı olarak etkiler.", hipotezini test etmek amacıyla yapılan regresyon analizi sonuçlarına göre; hizmet kalitesi bağımsız değişkeninin memnuniyeti $(\beta=, 466 ; \% 21,3)$ p<0,05 düzeyinde anlamlı, pozitif yönde etkilediği bulgusuna ulaşılmıştır. Bu veriden hareketle $\mathrm{H} 1$ hipotezi kabul edilmiştir.

Tablo 5: Hizmet Kalitesi Boyutlarının Memnuniyet Üzerindeki Etkisine Yönelik Regresyon Analizi

\begin{tabular}{|c|c|c|c|}
\hline Değişkenler & Beta & t değeri & p değeri \\
\hline \multirow[t]{2}{*}{ FÖ.-Mem. } & ,409 & 6,191 &, 000 \\
\hline & $\Delta R 2=, 163$ & $F=38,328$ & ,000 \\
\hline \multirow[t]{2}{*}{ Güv.-Mem. } & ,403 & 6,083 & ,000 \\
\hline & $\Delta R 2=, 158$ & $F=37,003$ & ,000 \\
\hline
\end{tabular}




\begin{tabular}{|c|c|c|c|}
\hline Hev.- Mem. & $\begin{array}{c}, 280 \\
\Delta R 2=, 073\end{array}$ & $\begin{array}{c}4,017 \\
F=16,139\end{array}$ & $\begin{array}{l}\text {,000 } \\
\text {,000 }\end{array}$ \\
\hline Güven Mem. & $\begin{array}{c}, 440 \\
\Delta R 2=, 189\end{array}$ & $\begin{array}{c}6,753 \\
F=45,602\end{array}$ & $\begin{array}{l}\text {,000 } \\
\text {,000 }\end{array}$ \\
\hline Emp.-Mem. & $\begin{array}{c}, 427 \\
\Delta R 2=, 178\end{array}$ & $\begin{array}{c}6,516 \\
F=\mathbf{4 2 , 4 5 5}\end{array}$ & $\begin{array}{l}, 000 \\
, 000\end{array}$ \\
\hline
\end{tabular}

Araştırmanın amacı doğrultusunda geliştirilen "H1a: Öğrencilerin fiziksel özellikler hizmet kalitesi algılarımemnuniyet düzeylerini pozitif ve anlamlı olarak etkiler.", "H1b: Öğrencilerin heveslilik hizmet kalitesi algıları memnuniyet düzeylerini pozitif ve anlamlı olarak etkiler.", "H1c: Öğrencilerin güvenilirlik hizmet kalitesi algıları memnuniyet düzeylerini pozitif ve anlamlı olarak etkiler.", "H1d: Öğrencilerin güvence hizmet kalitesi algıları memnuniyet düzeylerini pozitif ve anlamlı olarak etkiler." Ve "H1e: Öğrencilerin empati hizmet kalitesi alg ıları memnuniyet düzeylerini pozitif ve anlamlı olarak etkiler." hipotezlerini test etmek amacıyla yapılan regresyon analizi sonuçlarına göre; hizmet kalitesi boyutlarının her birinin memnuniyet değişkenini $p<0,05$ düzeyinde anlamlı, pozitif yönde etkilediği anlaşılmıştır. Memnuniyet değişkeni üzerinde hizmet kalitesi boyutlarından güven değişkeninin diğer değişkenlere oranla daha fazla açılayıcı etkisinin (\%18,9) olduğu görülmüştür. Güven değişkenini yaklaşık \%18 oranında empati değişkeni izlemektedir. Yani öğrencilerin memnuniyet düzeylerini artırmak istediğimiz takdirde öncelikle onların güvenlerini sağlamamız ardından empati değişkeni kapsamında onlarla bire bir özel olarak ilgilenmemiz gerektiği sonucuna ulaşılmıştır. Memnuniyet üzerinde en düşük oranda açıklayıcı etkiye sahip değişkenin ise heveslilik olduğu elde edilen bilgiler arasındadır. Bu verilerden hareketle geliştirilen hipotezler kabul edilmiştir.

Ayrıca araştırma kapsamında öğrencilerin demografik özelliklerine (cinsiyet, yaş, öğrenim gördükleri bölüm gibi) bağıı olarak hizmet kalitesine ve memnuniyet düzeylerine ilişkin algılarında bir farklılı̆ın olup olmadığı da belirlenmek istenmiş ve bu doğrultuda "H2: Öğrencilerin hizmet kalitesi algıları cinsiyetlerine göre farklılaşmaktadır.", "H3: Öğrencilerin hizmet kalitesi algıları yaşlarına göre farklıla şmaktadır.", "H4: Öğrencilerin hizmet kalitesi algıları öğrenim gördükleri bölüme göre farklılaşmaktadır.", "H5: Öğrencilerin memnuniyet düzeyleri cinsiyetlerine göre farklılaşmaktadır.", "H6: Öğrencilerin memnuniyet düzeyleri yaşlarına göre farklılaşmaktadır.", "H7: Öğre ncilerin memnuniyet düzeyleri öğrenim gördükleri bölüme göre farklılaşmaktadır." hipotezleri geliştirilmiştir. Geliştirilen hipotezleri test etmek amacıyla bağımsız t testi ve Anova anazlizlerinden faydalanılmıştır. Yapılan analizler neticesinde katılımcıların yaşlarına bağı olarak hizmet kalitesi algıları ve memnuniyet düzeyleri arasında anlamlı bir farklılığın oluşmadığı görülmüştür. Bu sebeple “H3” ve "H6” hipotezleri reddedilmiştir.

Tablo 6: Katılımcıların Cinsiyetleri Açısından Hizmet Kalitesi Algılarının ve Memnuniyet Düzeylerinin Farklılaşması

\begin{tabular}{|c|c|c|c|c|c|c|c|}
\hline Değişken & Cinsiyet & $\mathbf{N}$ & Ort. & Std. Sap. & $\begin{array}{l}\text { Serb. } \\
\text { Der. }\end{array}$ & $t$ & $p$ \\
\hline Hizmet & Kadın & 90 & 2,746 &, 870 & 194 & 3,082 & ,002 \\
\hline Kalitesi & Erkek & 106 & 3,119 &, 823 & & & \\
\hline \multirow[t]{2}{*}{ Memnun } & Kadın & 85 & 1,712 & ,954 & 182,501 & 3,464 & ,001 \\
\hline & Erkek & 101 & 2,270 & 1,244 & & & \\
\hline
\end{tabular}

Araştırmada yapılan bağımsız t-testi sonuçları incelendiğinde hizmet kalitesine ve memnuniyetlerine ilişkin genel olarak erkek öğrenciler ile kadın öğrenciler arasında istatistiksel olarak anlamlı bir farklılığın olduğu ve bu farklılığında erkek öğrenciler in kadın öğrencilere göre hizmet kalitesi algı ve memnuniyet düzeylerinin daha yüksek olmasından kaynaklı olduğu görülmüştür.

Tablo 7: Katılımcıların Öğrenim Gördükleri Bölümler Açısından Hizmet Kalitesi Algılarının Farklılaşması

\begin{tabular}{llllll}
\hline & Öğrenim Görülen Bölümler & A.O. & S.S. & F değeri & Anlm. Düzeyi \\
\hline \multirow{3}{*}{ Hizmet } & Yönetim-Organizasyon & 3,211 &, 782 & & \\
Kalitesi & Bitkisel-Hayvansal Üret. & 3,242 &, 812 & 6,138 &, 001 \\
& Sosyal Hizmet ve Danışmanlık & 2,471 &, 632 & & \\
& Mülkiyet Koruma ve Güvenlik & 2,919 &, 933 & & \\
\hline
\end{tabular}

Tablo 8: Katılımcıların Öğrenim Gördükleri Bölümler Açısından Memnuniyet Düzeylerinin Farklılaşması

\begin{tabular}{|c|c|c|c|c|c|}
\hline & Öğrenim Görülen Bölümler & A.O. & S.S. & F değeri & Anlm. Düzeyi \\
\hline \multirow{4}{*}{ Memnun } & Yönetim-Organizasyon & 1,917 & 1,143 & \multirow{4}{*}{3,373} & \multirow{4}{*}{,020 } \\
\hline & Bitkisel-Hayvansal Üret. & 2,348 & 1,285 & & \\
\hline & Sosyal Hizmet ve Danışmanlık & 1,492 & ,751 & & \\
\hline & Mülkiyet Koruma ve Güvenlik & 2,093 & 1,179 & & \\
\hline
\end{tabular}


Tablo 8 ve Tablo 9' da verilen ANOVA analizi sonuçları incelendiğinde öğrencilerin öğrenim gördükleri bölümler bazında hizmet kalitesi algılarının ve memnuniyet düzeylerinin birbirinden farklı olduğu bulgusuna ulaşılmıştır.

\section{SONUÇ VEÖNERILER}

İş dünyasının ihtiyaç duyduğu nitelikte işgücünü yetiştirerek işinin uzmanı ara elemanaçığını kapatma gayesiiçinde olan mes lek yüksekokulları için hizmet kalitesinin değerlendirilmesi ve kalitenin artırılması günümüzde rekabet ortamında yarışan tüm kurumlarda olduğu gibi yükseköğretim kurumları için de oldukça büyük önem taşımaktadır. Bu araştırmada, Kahramanmaraş Sütçü İmam Üniversitesi'ne bağ Iı Türkoğlu Meslek Yüksekokulunda öğrenim gören öğrencilerin fiziksel özellikler, güvenilirlik, heveslilik, güven ve empati olmak üzere beş boyuttan oluşan hizmet kalitesine ilişkin algılarının memnuniyetleri üzerindeki etkisini ölçmek amacıyla yapılmıştır. Araştırma verileri anket tekniği ile elde edilmiştir. Öğrencilere uygulanan anketler sonucunda elde edilen veriler için güvenilirlik analizi, frekans analizleri uygulanmıştır. Hipotezlerin test edilmesi için korelasyon, regresyon, bağımsız t-testi ile ANOVA analizleri kullanılmıştır.

Araştırmada yapılan frekans analizleri kapsamında hizmet kalitesi ve alt boyutlarının ortalamaları incelendiğinde en yüksek ortalamaya sahip boyutun heveslilik boyutu, en düşük ortalamaya sahip boyutun ise fiziksel özellikler boyutu olduğu görülmüştür. Buna göre öğr enciler meslek yüksekokulunda görevli akademik ve idari personelin kendilerine yardım etmeye istekli, problemlerini çözme ve öğrenme becerilerinin geliştirilmesi için çaba gösterdiklerini dile getirmektedirler. Bunun yanısıra öğrencilerin tüm fiziksel koşullar değerlendir ildiğinde yeterince kaliteli hizmet sunulmadığını ifade ettikleri görülmüştür. Öğrenciler öğrenim gördükleri binayı ve öğrenim mekanlarını yeterince modern görünüşlü bulmamakta, öğrenim mekanlarının temizlik, aydınlatma ve ısınma açısından yeterli olmadığını düşünmektedirler. Bu bilgi ışığında eğitim kalitesinin artırıması için gerekli olan fiziksel altyapının, teknoloji altyapısının iyileştirilmesinin gerekliliği dikkat çekmektedir.

Araştırmada yapılan bağımsız t-testi sonuçları incelendiğinde hizmet kalitesine ilişkin genel olarak erkek öğrenciler ile kadın öğrenciler arasında istatistiksel olarak anlamlı bir farklılı̆ın olduğu ve bu farklılı̆ında erkek öğrencilerin kadın öğrencilere göre hizmet kalitesi algı düzeylerinin daha yüksek olmasından kaynaklı olduğu görülmüştür. Buna göre kadın öğrenciler ile erkek öğrencilerin bakış açılarının birbirinden farklı olduğu, kadınların ayrıntılara daha fazla önem verdikleri, fiziksel özellikleri daha fazla önemsedikleri, beklentilerinin erkeklerden daha yüksek olduğu dolayısıyla kadınların hizmet kalitesi algılarının erkeklerden daha düşük olduğu sonucuna varılabilir. Bu duruma bağlı olarak da kadınlar erkeklere oranla daha az memnuniyet duymaktadırlar.

Yapılan korelasyon analizi sonucunda tüm hizmet kalitesi boyutları ile öğrenci memnuniyeti arasında pozitif yönlü anlamlı ilişkilerin olduğu görülmüştür. Diğer bir ifade ile hizmet kalitesi algıları arttığında öğrenci memnuniyeti de artmakta, hizmet kalitesine ilişk in algılar azaldığında, öğrenci memnuniyeti de azalmaktadır.

Öğrencilerin sunulan hizmetlere ilişkin algıladıkları kalitenin duydukları memnuniyet üzerindeki etkilerini incelemek amacıyla gerçekleştirilen regresyon analizi sonucunda da hizmetin tüm boyutlarına ilişkin algılarının memnuniyet düzeylerini istatiksel olarak anlamlı bir şekilde etkilediği belirlenmiştir.

Öğrencilerin öğrenim gördükleri bölümlere göre hizmet kalitesi algılarında ve memnuniyetlerinde bir farklıı̆̆ın olup olmadığının araştırıldığı ANOVA analizi sonuçları incelendiğinde de öğrenim görülen bölümlerin öğrencilerin genel olarak hizmet kalitesini değerlendirmede farklı düşünmelerine neden olduğu görülmüştür. Yine aynı şekilde öğrencilerin öğrenim görülen bölümler bazında farklı memnuniyet düzeyine sahip oldukları anlaşımıştır. Bu farkıııkların kaynağının ne olduğu yapılacak başka çalışmalarla ele alınıp değerlendirilebilir.

Bu araştırma bulguları ışığında meslek yüksekokulu kalitenin artırılması adına önceliği hangi hizmet boyutlarına vermesi ve iyileştirmelere gitmesi gerektiğine dair gerekli bilgilere ulaşmış olmaktadır. Hizmet kalitesinde istenilen sonuçlara ulaşabilmek için sınırlı kaynakların hang alanlara yatırılması gerektiği yönünde gerekli çabalar gösterilebilecektir. Ayrıca bu çalışma sonuçları Yükseköğretim Kalite Kurulu tarafından her yıl düzenli olarak üniversitelerden hazırlamasını istedikleri kurum iç değerlendirme raporları açısından da faydalı bilgiler içermektedir. Araştırma gerçekleştirildiği kurumun kendi güçlü ve zayıf yönlerini tanımasına olanak sunmakta, geliştirilmesi gerekli alanla rın belirlenmesine ışık tutmaktadır.

\section{KAYNAKÇA}

Cevher, E. (2016). Hizmet kalitesi açısından üniversitelere yönelik şikayetlerin incelenmesi. Journal of Yasar University, 2016, 11(43), s.163171.

Ceylan, M. (1997). Eğitimde toplam kalite yönetimi ve müşteri memnuniyeti. Kuram ve Uygulamada Eğitim Yönetimi Dergisi, 9(2), s.23-30.

Kalaycı, Ş. (2006). SPSS Uygulamalı Çok Değişkenli İstatistik Teknikleri, Ankara: Asil Yayınları.

Parasuraman, A., Zeithaml, V.A. ve Berry, L. L. (1988). SERVQUAL: A multiple-item scale for measuring consumer perceptions of service quality. Journal of Retailing, 64(1), pp.12-40.

Tayyar, N. ve Dilşeker, F. (2012). Devlet ve vakıf üniversitelerinde hizmet kalitesi ve imajın öğrenci memnuniyetine etkisi. Muğla Üniversitesi Sosyal Bilimler Enstitüsü Dergisi, Bahar, Sayı 28, s. 184-203.

Türkoğlu Meslek Yüksekokulu Birim iç Değerlendirme Raporu (2019). Erişim adresi

http://turkoglumyo.ksu.edu.tr/depo/belgeler/2019\%20Birim\%20\%C4\%B0\%C3\%A7\%20De\%C4\%9Ferlendirme\%20Raporu_20020314253534 73.pdf.

Yaşar, M. (2014). İstatistiğe yönelik tutum ölçeği: geçerlilik ve güvenirlik çalışması. Pamukkale Üniversitesi Eğitim Fakültesi Dergisi, Sayı 36 (Temmuz 2014/II), ss.59-75. 